\title{
Therapeutic Itinerary and Causes of Delay in Specialized Consultation of Patients Admitted for Diabetic Foot
}

\section{Comlan Jules Gninkoun1, Mensah S. Attikleme1, Roberto Dossou Torès Prudencio², Adébayo Sabi Cossi Alassani ${ }^{3}$, François Djrolo ${ }^{1}$}

\author{
${ }^{1}$ Endocrinology, Metabolism and Nutrition Unit, Faculty of Health Sciences of Cotonou, Cotonou, Benin \\ ${ }^{2}$ University Clinic of Internal Medicine and Medical Oncology, Cotonou, Benin \\ ${ }^{3}$ Teaching Hospital of Borgou-Alibori, Parakou, Benin \\ Email: julesla67@yahoo.fr
}

How to cite this paper: Gninkoun, C.J., Attikleme, M.S., Prudencio, R.D.T., Alassani, A.S.C. and Djrolo, F. (2018) Therapeutic Itinerary and Causes of Delay in Specialized Consultation of Patients Admitted for Diabetic Foot. Journal of Diabetes Mellitus, 8, 125-130.

https://doi.org/10.4236/jdm.2018.84012

Received: August 21, 2018

Accepted: October 8, 2018

Published: October 11, 2018

Copyright $\odot 2018$ by authors and Scientific Research Publishing Inc. This work is licensed under the Creative Commons Attribution International License (CC BY 4.0).

http://creativecommons.org/licenses/by/4.0/

(c) (i) Open Access

\begin{abstract}
Introduction: Amputation remains a common practice in patients admitted for diabetic foot. The delay in consultation is one of the main reasons. The objective of this work was to analyze patients' itinerary care and to identify the causes of delay in consultation in patients admitted for diabetic foot. $\mathrm{Me}$ thod: This is a descriptive cross-sectional study, including all patients hospitalized for diabetic foot. A wait of at least seven (7) days before consulting the Endocrinology department of Hubert Koutoukou Maga Teaching Hospital (CNHU-HKM) after the foot injury occurred was considered as delay in consultation. The data were recorded and analyzed in the EPI INFO software. The description of the sample was made according to the usual statistics (frequency, average, standard deviation). Results: Seventy-six (76) diabetic foot cases were admitted during the period of the study. The mean age of the patients was $56.64 \pm 10.71$ years with extremes of 29 years and 84 years. Patients were most often received at an advanced stage of the foot injury, 3D stage of Texas classification in $87 \%$ of cases and Wagner grades 4 and 5 in $52 \%$ of cases. The amputation rate was $38.16 \%$. An analysis of the first care places reveals that $90.8 \%$ of patients had consulted conventional medicine, $13.2 \%$ in traditional medicine; $1.2 \%$ had religious practices and $18.7 \%$ had declared self-medication at home. Consultation period at CNHU HKM was more than 7 days in $80 \%$ of cases and less than 7 days in $20 \%$ of cases. The average consultation time was $44.08 \pm 26.43$ days with extremes of 1 and 480 days. The main reasons for the delay in seeking hospital care cited by diabetic patients were fear of amputation (47.8\% of cases), economic difficulties (32.5\% of cases) and awareness lack of the situation seriousness $(22.4 \%)$. Conclusion: The therapeutic itinerary of patients with diabetic foot was par-
\end{abstract}


ticularly long. The main reasons of late appeal to specialized care were fear of amputation and economic difficulties. The implementation of universal health insurance and an information, education and communication program could certainly reduce the periods allowed for recourse to care and therefore to reduce the amputation rate.

\section{Keywords}

Therapeutic Itinerary, Diabetic Foot, Delay, Complication, Amputation

\section{Introduction}

Diabetes is a real public health problem because of its economic weight and its silent evolution [1]. It is a serious disease because of its complications. In Sub-Saharan Africa, the total population of diabetics in 2017 was estimated at 16 million and the estimates in 2045 are 41 million [2]. In Benin, diabetes prevalence rose from $1.1 \%$ in 2001 [3] to $2.6 \%$ in 2008 [4]. In terms of diabetes complications, diabetic foot is relatively common and is responsible for a very high morbidity and mortality. Diabetic foot represents one of the main causes of amputation in the world after road accidents [5]. Today, despite advances in vascular surgery and medical monitoring of diabetics, amputation remains a common practice because of the lack of access to health facilities and customary beliefs leading the majority of patients to use partially or exclusively traditional medicine [6]. It is observed that diabetic patients consult often late for managing diabetes or its complications including diabetic foot. This observation of the late appeal to specialized care justifies this study, whose objectives were to analyze the course of patients seeking care and to identify the causes of delay in consultation in patients admitted for diabetic foot.

\section{Material and Study Method}

It is a cross-sectional, descriptive study with a retrospective phase and a prospective phase. This study took place during 31 months (1 January 2014 to 31 July 2016) in Endocrinology department of Hubert Koutoukou Maga Teaching Hospital (CNHU-HKM) Cotonou. It's a level 1 reference hospital (last level of reference) and most diabetic foot cases are received there. Moreover there is a possibility of direct consultation for any patient without going through intermediate levels. It was a systematic census of all diabetic patients hospitalized for the first time for diabetic foot. A standardized survey sheet prepared for the study was used to collect socio-demographic data, the number of health centers visited, the perception of the disease, physical examination data and paraclinical tests. In case of missing data, patients were contacted by telephone for further information after free and informed consent. A wait of more than seven (7) days before consulting an endocrinology department after the foot injury occurred was considered as delay in consultation. The therapeutic itinerary was defined as the 
succession of places where care was sought since the first foot injury occurred. The different places of recourse to defined care were conventional medicine (medical care place where health professionals practice), traditional medicine (care place of traditional healers), religious practices (houses of prayer) and self-medication at home.

The data were recorded and analyzed in the EPI INFO software. Sample description was made according to the usual statistics (frequency, mean, standard deviation).

\section{Results}

\subsection{General Characteristics of the Population}

Seventy-six (76) new cases of diabetic foot were admitted during the study period. The average age of the patients was $56.64 \pm 10.71$ years with extremes of 29 and 84 years. Among the patients included, $55.30 \%$ were male with a sex ratio of 1.23 . Practitioners of the Catholic religion were represented in $57.90 \%$ of cases. Concerning the level of education, $81.6 \%$ of patients were in school and $23.7 \%$ had a university level. Almost half of the patients (46.1\%) lived outside the city of Cotonou. In the study population, $35.50 \%$ of patients were employees; $28.90 \%$ were shopkeepers and $34.20 \%$ were craftsmen and housewives. In addition, patients were most often seen at an advanced stage of foot injury, Texas 3D stage in $87 \%$ of cases and Wagner grades 4 and 5 in $52 \%$ of cases. The amputation rate was $38.16 \%$.

\subsection{Therapeutic Itinerary of Patients}

Places analysis of first recourse to care reveals that $90.8 \%$ of patients had consulted in conventional medicine, $13.2 \%$ in traditional medicine, $1.2 \%$ had recourse to religious practices and $18.7 \%$ had declared self-medication at home. In our study population, $80.30 \%$ of patients had visited a health facility before their admission to CNHU; $15.80 \%$ of patients had visited 2 health facilities and in $3.90 \%$ of cases, no facilities had been visited before recourse to CNHU. And in the reference channel, $55.30 \%$ patients had been referred to CNHU by the health facility visited and in $43.40 \%$ of cases it was a personal initiative of the patient. In our sample, 8 patients have resorted to traditional medicine and in $87.5 \%$ of the cases; the duration of stay for these patients in the traditional medecine was between 2 and 15 days before their admission to CNHU. Moreover $49.9 \%$ of patients had a duration of stay more than 15 days in general medecine (Table 1).

\subsection{Causes of Delay in Endocrinology Consultation}

The consultation period at CNHU was more than 7 days in $80 \%$ of cases and less than 7 days in $20 \%$ of cases. The average consultation time was $44.08 \pm 26.43$ days with extremes of 1 and 480 days.

The main reasons for delay in hospital recourses cited by diabetic patients were fear of amputation ( $47.8 \%$ of cases), economic difficulties (32.5\% of cases) (Table 2). 
Table 1. Duration of stay of diabetic patients in healthcare facilities visited.

\begin{tabular}{ccc}
\hline Duration of stay in traditional medicine & Number & Percentage \\
\hline$<2$ days & 2 & 25.0 \\
{$[2-7]$ days } & 3 & 37.5 \\
{$[7-15]$ days } & 2 & 25.0 \\
$\geq 15$ days & 1 & 12.5 \\
Duration of stay in general medicine & & \\
$<2$ days & 9 & 11.8 \\
{$[2-7]$ days } & 10 & 13.2 \\
{$[7-15]$ days } & 19 & 25.0 \\
$\geq 15$ days & 38 & 49.9 \\
\hline
\end{tabular}

Table 2. Main reasons for delay in hospital recourse cited by diabetic patients.

\begin{tabular}{ccc}
\hline Reasons & Number & Percentage (\%) \\
\hline Fear of amputation & 35 & 47.8 \\
Economic difficulties & 25 & 32.5 \\
No perception of the seriousness of the situation & 17 & 22.4 \\
Painlessness of the initial lesions & 4 & 5.3 \\
Fear of diagnosis & 3 & 3.9 \\
Ignorance & 2 & 2.6 \\
\hline
\end{tabular}

\section{Discussion}

The fact that this study was conducted in a single center did not allow several patients to be enrolled. And we mention that this was a cross-sectional study with a descriptive purpose, these results are fundamental for two reasons: firstly, all cases that reached the CNHU HKM in the reference service of Benin for the diabetic foot care were recruited and secondly, several data, in particular the reasons for delay in the specialized consultation, were collected directly from the patients and not only by exploitation of their medical records.

In epidemiological terms, the mean age of the patients was $56.64 \pm 10.71$ years, which are close to that of B. Tchakonté and Col [1] who had found in Cameroon in 2005, a mean age of $57 \pm 9$ years and that observed by E. Khadraoui et al. [7] which was $56.6 \pm 11.8$ years.

A small proportion of patients were illiterate. BOKO [8] also noted in his study a small proportion (26.7\%) of illiterates. This low illiteracy rate, which contrasts with the high illiteracy rate in Benin, could be explained by the fact that this study was conducted in urban areas where the scolarisation rate is higher.

In our study, patients had a particularly long itinerary before having recourse to the referral centre, with an average consultation period of 44 days in our study. This long period of consultation in specialized environment has been re- 
ported by Djibril et al. [9] who had found an average of 33 days consultation with extremes from 6 to 120 days. The painless nature of the initial lesions and socio-economic factors (32.5\% of the reasons found in our work) can be incriminated. The fact that the lesions are discovered fortuitously or are painless was also reported by D. SANO [10] which, in his study in Ouagadougou, found that $69 \%$ of diabetic foot appeared spontaneously and painlessly. Patients were then seen at an advanced stage of lesions as found in our study: $87 \%$ in Texas 3D stage or $52 \%$ in Wagner grades 4 and 5 with a very high risk of amputation. TIENO [11] in Burkina Faso had also found in his study foot lesions classified mainly in grades 4 and 5 by Wagner and the same observation had recently been made by Djibril et al. [9] in Togo in 2018. The main reason for the delay to hospital recourse by diabetic patients was fear of amputation ( $47.8 \%$ of cases).

Apart from the well-known economic difficulties, knowing that Benin doesn't have universal health insurance and most of the patients have to take charge of their health problem, there is also the fear of amputation.

This fear of amputation is actually a "double-edged knife" for two reasons. First, patients are seen late at Wagner grade 4 or 5 or Texas 3D in a context of severe sepsis and the impossibility of any revascularization imposing an amputation.. There is therefore a high rate of amputation, most often major, reported in African studies. Indeed, the amputation rate in our study was $38.16 \%$ and Kérékou A. et al. [12] had found in the same service in 2015 a similar amputation rate of $32 \%$. Moreover, Djibril et al. [9] recently reported an amputation rate of $51.61 \%$ in their work in Togo. Second, the population's plausible perception of this high rate of amputation as a fatality will reinforce the fear that is often reported. Finally, this fear will be responsible for a delay in the consultation. Since patients are seen in advanced stages of injury, amputation is often the only treatment option. This vicious circle situation is sometimes aggravated by promises of healing through treatments not proven by some traditional healers, as we have reported in our work that $10.5 \%$ of subjects used traditional medicine. There is therefore a need to strengthen therapeutic patient education and communication with the population in order to break this vicious circle.

\section{Conclusion}

Therapeutic itinerary of patients with diabetic foot was particularly long. The main reasons of late appeal to specialized care were fear of amputation and economic difficulties. The implementation of universal health insurance and an information, education and communication program could certainly reduce the time taken to seek care and therefore to reduce the amputation rate.

\section{Conflicts of Interest}

The authors declare no conflicts of interest regarding the publication of this paper.

\section{References}

[1] Tchakonté, B., Ndip, A., et al. (2005) Le pied diabétique au Cameroun. Bulletin de la 
Société de Pathologie Exotique, 2, 2-5.

[2] (2017) Atlas IDF, 8 iéme Edition.

[3] Djrolo, F., Amoussou, K.D., Zannou, D.M., Houinato, D., Ahouandogbo, F. (2003) Houngbé. Prévalence du diabètesucré au Bénin. Louvain Médical, 122, 256-260.

[4] Fambo, D. (2008) Prévalence de l'hyperglycémie et de l'hypercholestérolémie en population générale au Bénin en 2008. Thèseméd., Cotonou, 1404.

[5] Richard, J.L. and Schuldiner, S. (2008) Epidémiologie du pied diabétique. La Revue de Médecine Interne, 29, S222-S230. https://doi.org/10.1016/S0248-8663(08)73949-3

[6] Gning, S.B., Thiam, M., Fall, F., et al. (2007) Le diabète sucré en Afrique subsaharienne: aspects épidémiologiques, difficultés de prise en charge. Méd Trop, 67, 607-611.

[7] Khadraoui, E., Fendi, O., Gaigi, I., Trabelsi, N., Trimesch, A. and Benmami, F. (2012) Facteurs favorisants les lésions des pieds chez le diabétique. Diabetes \& Metabolism, 38, A112-A124. https://doi.org/10.1016/S1262-3636(12)71458-1

[8] Boko, M. (2014) Prévalence du diabète sucré dans la population adulte de Porto-Novo. Thèse, Faculté de médecine de Porto-Novo, Bénin, No. 004.

[9] Djibril, A.M., Mossi1, E.K., Djagadou, A.K., Balaka, A., Tchamdja, T. and Moukaila, R. (2018) Pied diabétique: aspects épidémiologique, diagnostique, thérapeutique et évolutif à la Clinique Médico-chirurgicale du CHU SylvanusOlympio de Lomé. Pan African Medical Journal, 4. https://doi.org/10.11604/pamj.2018.30.4.14765

[10] Sano, D., Tieno, H., Drabo, Y. and Sanou, A. (1999) Prise en charge du pied diabétique. A propos de 42 cas au $\mathrm{CHU}$ de Ouagadougou. Médecine d'Afrique Noire, 46, 307-311.

[11] Tieno, H. (1996-1997) Les lésions du pied chez le diabétique au centre hospitalier national YalgadoOuedraogo de Ouagadougou. Thèse, Faculté de Sciences de la Santé de Ouagadougou, Burkina-Faso.

[12] Kerekou Hode, A., Djrolo, F. and Amoussou-Guenou, D. (2015) Epidemiological and Clinical Features of Diabetic Foot in Cotonou. Journal of Diabetes Mellitus, 5, 173-180. https://doi.org/10.4236/jdm.2015.53021 